\title{
EL CUENCO DE VIDRIO TARDORROMANO CON GOTAS Y CABUJONES DE GUARROMÁN, JAÉN
}

\author{
LATE-ROMAN GLASS BOWL WITH DROPS AND CABOCHONS FROM GUARROMAN, JAEN
}

MARÍA JOSÉ ALMAGRO GORBEA

Museo Nacional de Artes Decorativas

La colección de vidrios romanos del Museo Nacional de Artes Decorativas de Madrid conserva una importante pieza, ya conocida por alguna cita en publicaciones científicas, pero que no ha recibido nunca el estudio específico que por su interés merece.

Se trata de un cuenco procedente de la antigua colección reunida a comienzos del siglo XX por D. José Sánchez Garrigós, que fue comprada por el Estado para el Museo en el siglo pasado. Según la documentación obtenida en los expedientes del Museo Nacional de Artes Decorativas, D. José Sánchez Garrigós ofreció en venta al Museo un conjunto de 136 piezas de vidrio de época antigua, junto con otras piezas más modernas, de origen catalán y andaluz principalmente. Por Orden Ministerial de 9 de enero de 1935 se aceptó la oferta y se compraron todas las piezas por cuarenta y seis mil pesetas de la época, cantidad entonces nada despreciable, ya que se trataba de una colección de calidad, por lo que dicho precio no fue excesivo, teniendo en cuenta la cantidad, la calidad y la gran variedad de los objetos de vidrio que la integraban. También consta que todas las piezas de la Colección Sánchez Garrigós se registraron en el Museo de Artes Decorativas pocos días después de la citada Orden Ministerial de compra, el 14 de enero, siendo inventariados con los números antiguos de inventario del 3744 al 3792. Posteriormente recibieron un nuevo número de inventario, pues en las fichas más modernas aparecen numeradas del número 594 al 758. El cuenco que aquí se estudia fue registrado al ingresar en el Museo con el número 148-6, y posteriormente inventariado con el $\mathrm{n}^{\circ}$ 3751 del inventario antiguo, y más recientemente con el n ${ }^{\circ}$ CE00741.

\section{LA COLECCIÓN SÁNCHEZ GARRIGÓS}

Don José Sánchez Garrigós, el antiguo propietario del cuenco, según el citado expediente del Museo de Artes Decorativas, era natural de Alicante, pero residía en Barcelona, donde debió reunir a lo largo de los años su colección de vidrios antiguos, aunque su colección constaba, como ya se ha dicho, de algunos vidrios de época moderna. Según el citado expediente de compra, los vidrios antiguos, prerromanos y romanos, junto con algunos árabes, procedían de diversos lugares $\mathrm{y}$, concretamente, se dice que algunos, sin especificar cuáles ni dar datos, procedían de Ampurias. Otros seis ejemplares de dimensiones mayores se dice que eran del centro de España, y también se indica que varias piezas provendrían de Andalucía, como asimismo había piezas de origen Oriental, que debió de adquirir a través de anticuarios. Sin embargo, todos estos datos son poco precisos, y en la mayoría de los casos no podemos saber con seguridad ni el origen ni la procedencia exacta de los objetos.

El conjunto de la Colección es bastante coherente, y fue formado siguiendo criterios válidos para comprender la historia general del vidrio en la Antigüedad. Aunque la mayor parte de las piezas no son de primera categoría, en general son muy representativas de los productos de vidrio antiguos más interesantes y frecuentes que han circulado por el Mediterráneo, desde el periodo arcaizante griego, que estudiosos del vidrio denominan Mediterráneo I, hasta la época islámica antigua. La colección incluye productos fabricados en pasta de vidrio, realizados con el método del núcleo de arena, como una rica serie de alabastrones, arybalos, oinochoes y anforiscos adornados con hilos policromos de vidrio incrustados, de los Grupos Mediterráneo I, II y III de Harden y Grose, así como algunos collares y sortijas para el adorno personal hechos de pasta de vidrio, con los métodos y formas corrientes en estos «abalorios».

La mayoría de las piezas de la Colección de Sánchez Garrigós son vidrios soplados de época romana, a la que corresponde el cuenco objeto de este estudio. Entre ellas hay diversas botellas cuadradas y cilíndricas de las formas Isings 50 y 51 , algunas jarras representativas de las diferentes etapas y productos del vidrio datables en los siglos III y IV d.C. y vasos para beber, cuencos para comer, un plato, alguna taza para 

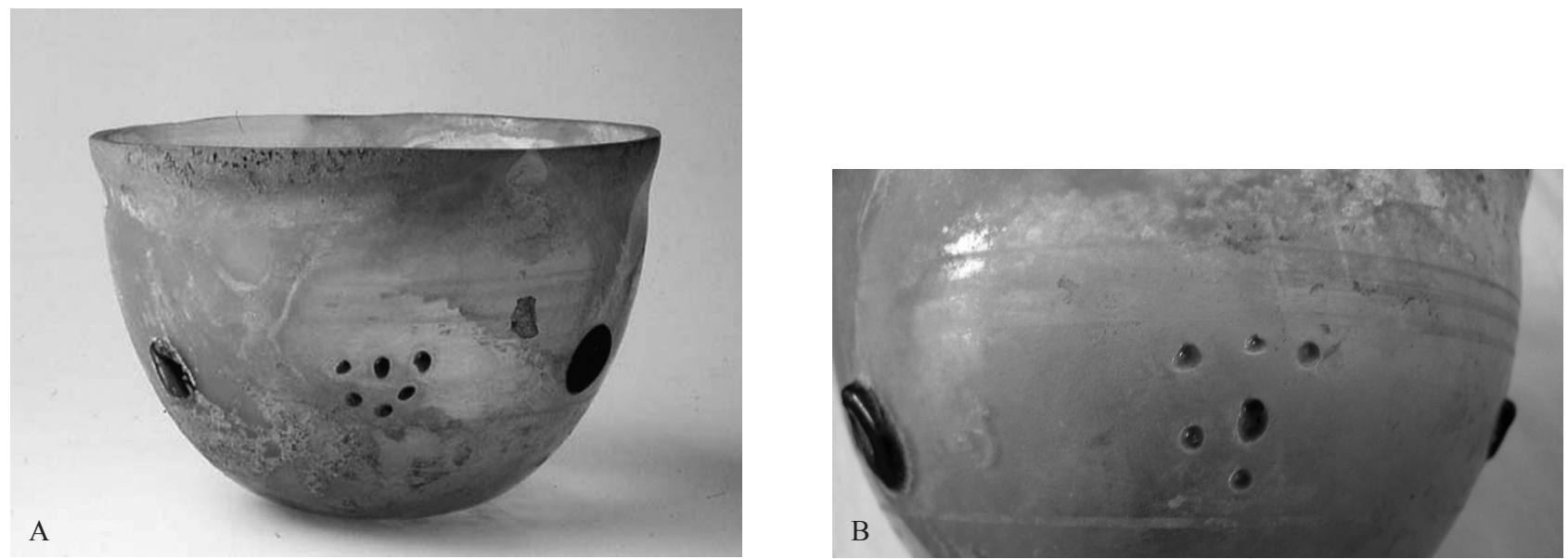

Figura 1: Cuenco del Museo Nacional de Artes Decorativas con gotas de vidrio coloreado y líneas grabadas, y detalle del mismo.

líquidos, todas ellas formas corrientes dentro de la vajilla en vidrio soplado romana, de cronología muy amplia. Igualmente destaca un fragmento de «cornu potorio» o cuerno, realizado en vidrio de color melado, de los que se conocen en España muy escasos ejemplares, por ser una pieza de importación de datación dudosa, quizás del siglo II d.C. El conjunto más numeroso lo forman los ungüentarios de vidrio soplado, de formas globulares o piriformes antiguas, que se fechan en el periodo de Augusto-Tiberio o Tiberio-Claudio. Más numerosos son los ungüentarios tubulares de la forma Isings 8, del periodo flavio-trajaneo, aunque siguen utilizándose en los siglos II y III d.C., y pueden ser coetáneos de la forma Isings 28 , también representada en la colección. Por el contrario, son escasos los ungüentarios de formas acampanadas de forma Isings 82, denominados de «lampadario», ya datados en los siglos siguientes. Entre los frascos, destaca un ejemplar en forma de racimo de uvas y otro en forma de higo chumbo, así como una pequeña e interesante colección de frasquitos para cosmética o para contener khool, adornados con hilos de vidrio que recuerdan algunos de los productos antiguos en pasta vítrea, piezas que deben situarse a partir del siglo IV d.C.

La escasa y poco precisa documentación que conserva el Museo de Artes Decorativas indica que muchas piezas de esta colección procederían de saqueos y excavaciones clandestinas, en su gran mayoría realizadas en necrópolis de diversos lugares de la Península Ibérica, como era frecuente en años anteriores a la Guerra Civil y aun después, dados los buenos precios que estos objetos adquirían en los anticuarios para satisfacer y surtir a los coleccionistas, hecho favorecido al no existir leyes tan drásticas como las actuales, que penalizasen los saqueos, por lo que eran frecuentes los desvalijadores profesionales de tumbas, que surtían a los anticuarios con los hallazgos. Esta procedencia debe atribuirse a casi todas las piezas de vidrio de la Colección Sánchez Garrigós del Museo Nacional de Artes Decorativas, pues, aunque el expediente de compra indica que muchos objetos vienen de Ampurias, del interior de la Península o de Andalucía, es muy probable que algunos puedan venir también de las Baleares, concretamente de Ibiza, donde eran numerosos los hallazgos de vidrios, generalmente ungüentarios, fabricados en pasta de vidrio o vidrio soplado. Pero también hemos podido comprobar que buen número de estos recipientes de vidrio son de origen oriental, por lo que han debido llegar a España a través del comercio de antigüedades.

La ficha de catalogación de este cuenco decorado con cabujones verdes y azul oscuro indica que procede de Guarromán, provincia de Jaén, según datos ya publicados por Vigil $(1969,158)$, quien, a su vez, los tomó de la Historia de España de Menéndez Pidal (1940, 661). Sin embargo, no existe documentación segura que corrobore la certeza de dicha procedencia, que, además, tampoco consta en el expediente de compra de la pieza en el Museo Nacional de Artes Decorativas.

\section{EL CUENCO CON CABUJONES}

\section{Descripción:}

Este cuenco de vidrio corresponde a la conocida forma Isings 96b2, Morin-Jean, 71-73, Arveiller-Dulong, $\mathrm{n}^{\circ}$ 209-210, que aparece decorado con cabujones o goterones de vidrio (Figs. 1-2).

Dicho tipo de cuencos se caracterizan por un depósito de forma semiesférica, bastante alto, con boca recta que, en ocasiones, termina con la parte superior ligeramente exvasada. El vidrio suele ser claro, más o menos grueso y transparente, pero casi siempre incoloro, con tonalidades verdes o amarillentas. Las paredes externas del depósito aparecen decoradas con una serie de pequeñas gotitas de vidrio coloreado que pueden alternar con otras en forma de gruesos cabujones, unas y otras compuestas por pegotes más o menos grandes y circulares de vidrio de tonos fuertes, generalmente de color azul oscuro intenso, violeta, vino o verde, que destacan sobre la superficie clara del recipiente a 

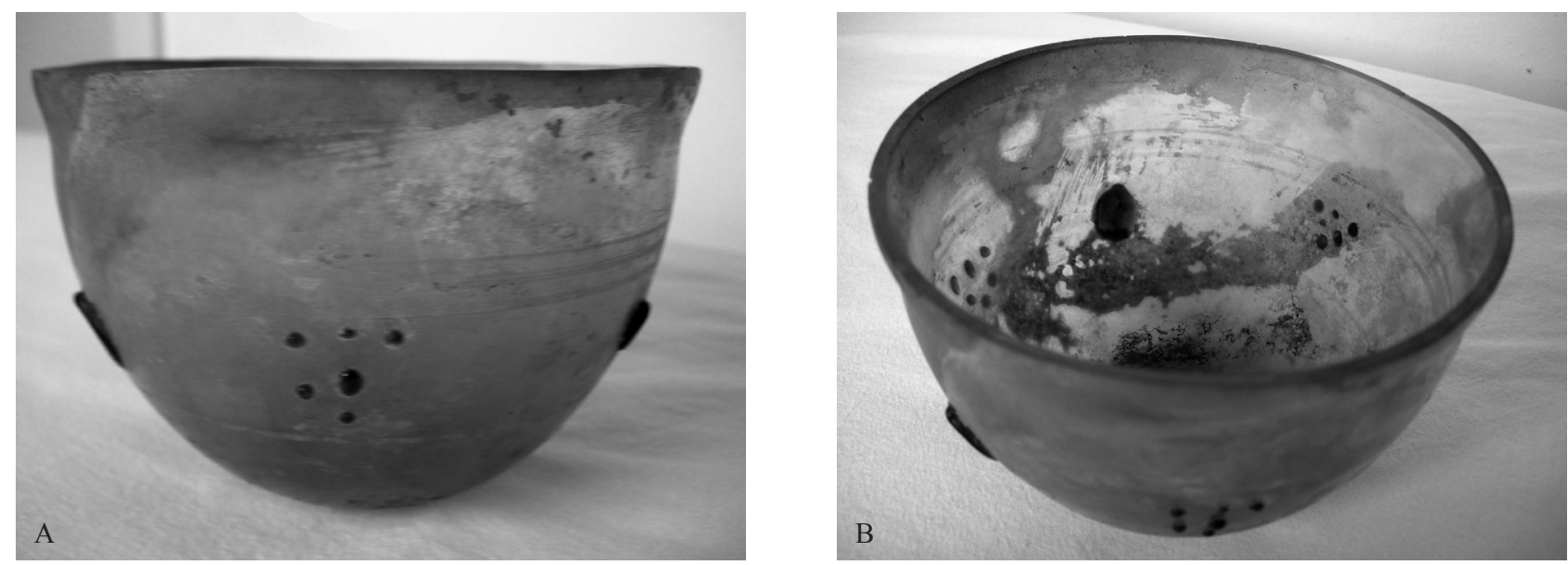

Figura 2: Reverso y vista superior del vaso, con las gotitas verdes enmarcada por las líneas grabadas a torno.

modo de incrustaciones de piedras preciosas, ya que estos vasos, de cronología tardía (vid. infra), suelen imitar en vidrio piezas ricas de metal de las vajillas suntuarias romanas utilizadas en la Baja Época.

El cuenco del Museo de Artes Decorativas corresponde a la citada forma Ising 96b2, pues presenta el depósito de forma circular con la base redondeada, aunque ligeramente rehundida en el centro para poder sostenerse mejor. La embocadura está algo inclinada al exterior, pero tiene el borde recto, con el corte seco y algo pulido. Las paredes del recipiente ofrecen la característica decoración de cabujones de tipo «a» (Fig. $1, a-b)$, conseguidos por la adhesión en caliente sobre la superficie exterior de pegotes grandes y pequeños de masa vítrea de color azul verdoso oscuro y verde fuerte, habiendo sido aplanados posteriormente los de tamaño grande para darles forma de cabujones.

La decoración resulta muy característica. Hacia la mitad del cuenco, alternan un grueso goterón o pegote ovalado de masa vítrea de color azul verdoso oscuro, en forma de cabujón circular aplanado, con seis diminutas gotitas apuntadas de color verde fuerte y de la misma técnica, dispuestas formando un triángulo en forma de racimo. Estos motivos se repiten hasta tres veces alrededor del cuenco, de manera que éste ofrece tres gruesos cabujones azules y tres grupos de seis gotitas de color verde. Enmarcando esta franja central, encima de la misma y a la altura del tercio superior del vaso, éste ofrece tres líneas paralelas esmeriladas realizadas a torno, que bordean todo el recipiente, $y$, bajo este motivo decorativo, aparece otra línea similar grabada con la misma técnica (Figs. 1,b y 2,a-b).

$N^{o}$ de Registro: $148-6$

$N^{o}$ de Inventario: CE00741 (3751 antiguo).

Materia: Vidrio incoloro ligeramente verdoso transparente, Pantone 383-C, y azul oscuro opaco, Pantone 2965-C.

Técnica: Soplado al aire, adhesión de gotas de vidrios de color en caliente y líneas de esmerilado realizadas a la rueda.
Medidas: Altura: 9, $4 \mathrm{~cm}$. Diámetro máximo: 13, $8 \mathrm{~cm}$. Grosor: entre 4 y $3,5 \mathrm{~mm}$.

Cronología: Siglo IV d.C.

Procedencia: Según los datos publicados (Menéndez Pidal [dir.], 1940, 661), la pieza procedería de Guarromán, en la provincia de Jaén.

Conservación: El vidrio es bastante grueso para este tipo de vasos, incoloro y semitransparente en la actualidad, debido a las concreciones que ostenta, con tonalidades ligeramente verdosas. Presenta algunas irisaciones y burbujas. Su estado es relativamente bueno, pero tiene oxidación laminar con algunas exfoliaciones en ciertas zonas de las paredes externas, así como numerosas concreciones, la mayoría de tipo terroso, por toda la superficie, tanto interna como externa, que impiden constatar bien el estado presente y la coloración del vidrio (Fig. 2b).

Paralelos: Este tipo de vaso de vidrio es bastante frecuente tanto en Oriente como en Occidente. Se caracterizan por presentar casi siempre en sus paredes una decoración de gotas siguiendo tres tipos básicos, que son los más frecuentes, con algunas variantes, los cuales se detallan a continuación.

Tipo «a» (Fig. 3,a-b), como el del ejemplar del Museo de Artes Decorativas de Madrid. Ofrece alternancia de gotas grandes con pequeñas gotitas de vidrio, generalmente en color azul fuerte o violáceo, pero en ocasiones también de otros colores, como verde o rojo vinoso, dispuestas en racimos por lo general de tres, cinco o seis gotitas respectivamente, colocadas en una ancha faja central, generalmente, aunque no siempre, encuadrada entre varias líneas paralelas grabadas a torno.

Tipo «b». Es más simple que el anterior, normalmente empleado en las formas Isings 106-107. Suele ofrecer una única hilera horizontal de gruesos cabujones mas o menos circulares o irregulares, formados por gruesas gotas de vidrio de colores igualmente 

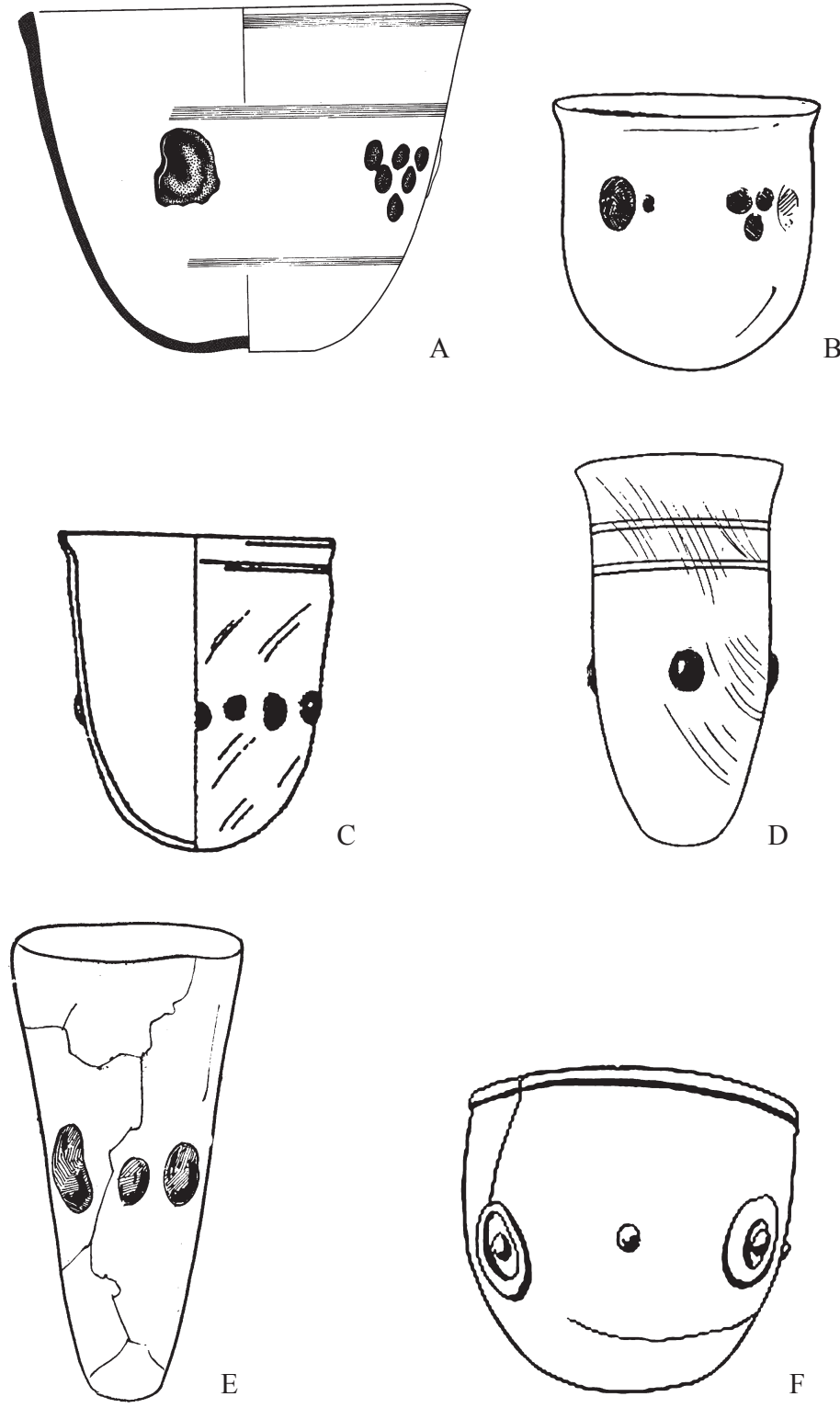

Figura 3: Decoraciones de cuencos con cabujones hallados en Chipre, Hispania y las Galias. a) Chipre, Col. Palma di Cesnola; b) Ilici, Alicante; c) Sablonière, Aisne; d) Reims; e) Estrasburgo; f) Vieil-Atre (a, c-f, según Morin-Jean; b, según Sánchez de Prado).

fuertes, en tonalidades parecidas a las del tipo anterior (Fig. 3,b y f).

Tipo «c». Este tipo de decoración ya no es tan frecuente como la anterior. Consiste en una franja decorativa en el centro del vaso en la que alternan un goterón o cabujón grande con otra gotita más pequeña, realizadas todas siempre en tonalidades fuertes. Este tipo de decoración aparece tanto en cuencos de las formas Isings 96 como en los recipientes de las formas Isings 106 y 107 (Fig. 3,d-e).

Otros tipos de decoraciones (Fig. 4,a-c) ya no tienen una dispersión tan grande como las anteriores ni son tan frecuentes. Suelen aparecer en la zona septentrional de las Galias y, sobre todo, en la Baja Renania, en torno a Colonia, donde la disposición de los cabujones de gotas de vidrio en muchas ocasiones se hace más elaborada, compleja y vistosa. Además, en estas regiones los recipientes con los tipos de decoración anteriormente citados se adornan con un mayor numero de cabujones o goterones de vidrio, que pueden en ocasiones llegar a ofrecer cincuenta gotas de diferentes colores, alternados de maneras muy variadas y ricas, e, incluso, su policromía suele ser mucho mas diversa, con tonos azules, amarillos, verdes, rojos, marrones, blancos, etc., como algunas piezas del Museo de Colonia (Fremersdorf, 1962, no 14, 15) y de Estrasburgo (Arveiller-Dulong, 1985), todas ellas de la forma Isings 106, con reiteración de motivos decorativos del tipo «a» en dos franjas superpuestas arriba y abajo del recipiente, delimitadas entre líneas paralelas grabadas a torno (Fig. 4,c). Los colores de dichos cabujones son más variados, pues la pieza de Estrasburgo 

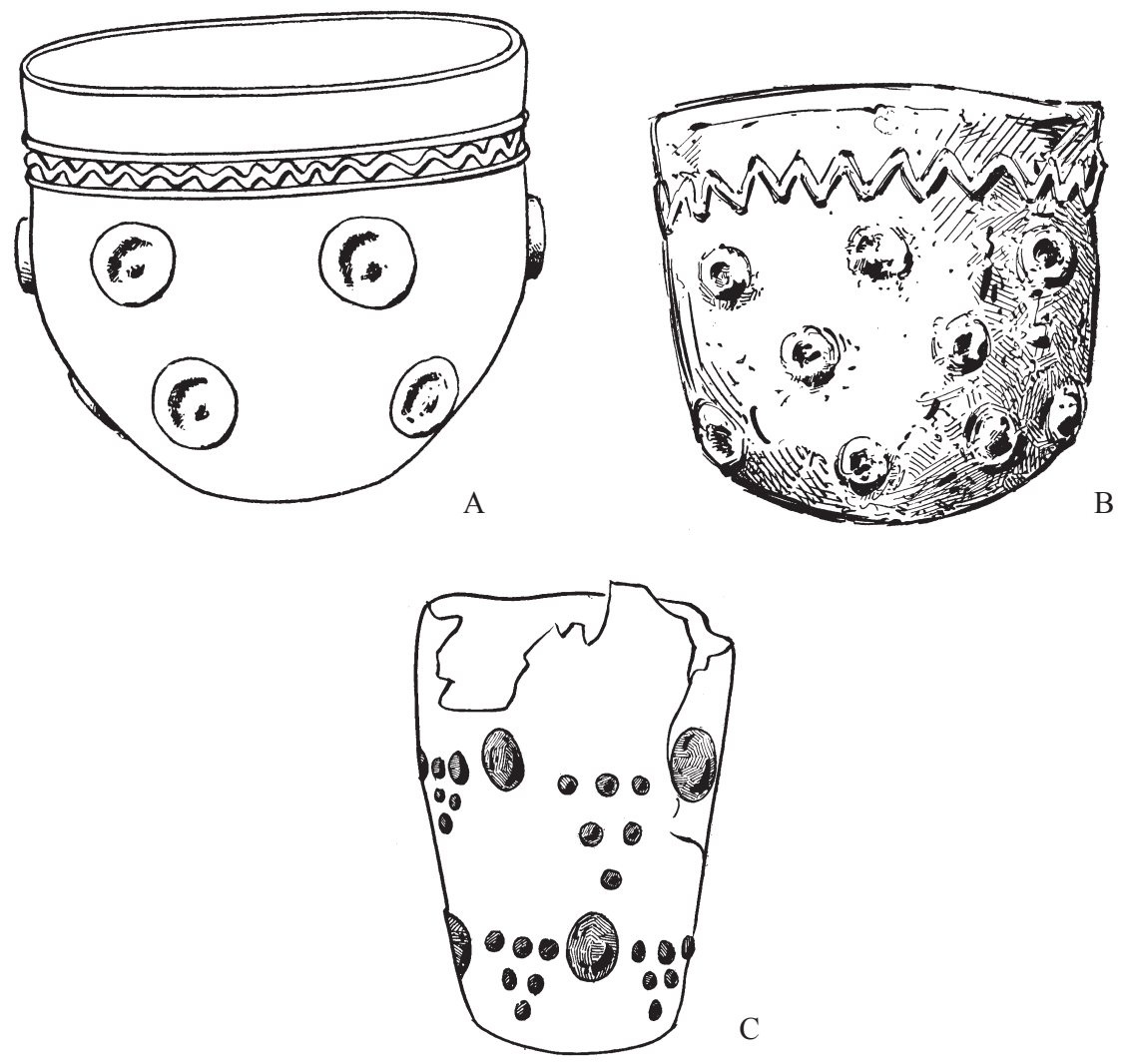

Figura 4: Cuencos con cabujones hallados en las Galias: a) Brény, Aisne; b) Beauvais; c) Estrasburgo (según Morin-Jean).

alterna verdes y marrones, y las de Colonia, marrones y amarillas. La pieza de Estrasburgo apareció en una tumba de la Porte Blanche fechada entre fines del siglo III y el siglo IV d.C. Además, en las Galias y en la Renania los cabujones pueden ser lisos o umbilicados, es decir, realzados con un umbo central, más o menos sobresaliente (Figs. 3, f y 4,a-b-c).

Se ha discutido mucho sobre el origen de este tipo de vasos. Para unos estaría en Occidente, tal vez en Colonia, donde se han encontrado las piezas más elaboradas y bellas de esta clase, y tal vez también las más antiguas, según algunos estudiosos, como Fremersdorf (1962), quien fecha algunos vasos ya en el siglo III d.C. Desde allí pasarían a Italia, al Valle del Danubio y a Hungría, donde han aparecido también muchos ejemplares (Calvi, 1968, 170-1; Sternini, 1995, Fig. 16; Curina, 1983, 167; Filarska, 1952). Para otros investigadores, podrían existir varios focos de origen, uno oriental y otros occidentales, uno de éstos en Colonia, iniciado hacía el siglo III d.C., junto a otro posiblemente en Italia (Fremersdorf, 1967, 131-5). Sin embargo, cabe suponer que los primeros tipos de estos recipientes pudieran proceder de Oriente, donde han aparecido numerosas piezas con los motivos decorativos más sencillos y primitivos, de tipos «a» $\mathrm{y}\langle\mathrm{b} »$ (vid. supra), y desde Oriente podrían haber pasado a distintos focos de Occidente, ya que se conocen bastantes cuencos y vasos decorados con cabujones de procedencia oriental segura en diversos museos del mundo.
Por ejemplo, el British Museum de Londres posee dos ejemplares de este tipo de decoración procedentes de Chipre, de la antigua Colección de Palma di Cesnola (Harden, 1988, $\mathrm{n}^{\circ}$ 44, 113). Uno de ellos es más alto que el del Museo de Artes Decorativas, pero está muy bien conservado, es de factura excelente y de decoración más cuidada, bien depurada y mejor terminada (Fig. 5), aunque presenta alguna pequeña

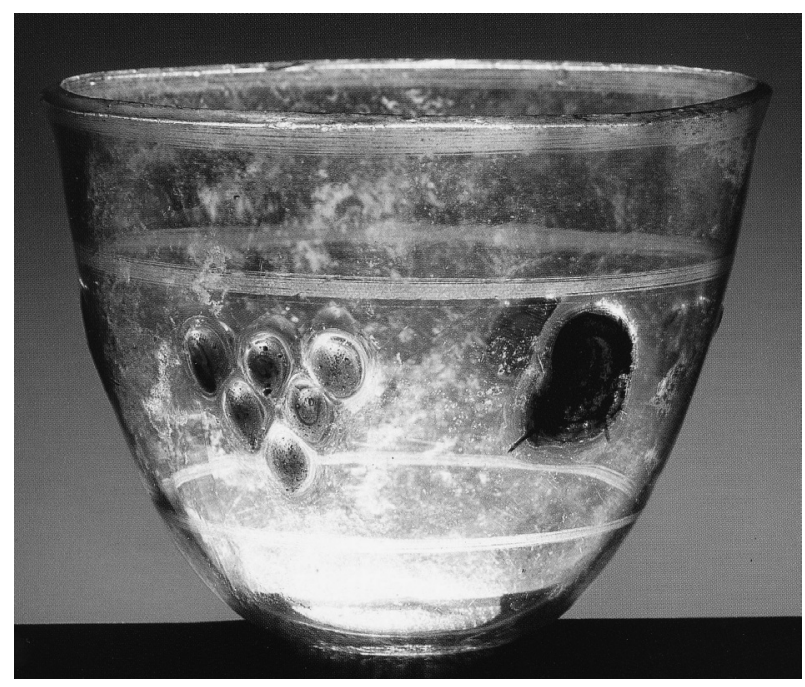

Figura 5: Vaso de vidrio con decoración de cabujones azules de la Colección Palma di Cesnola, Museo Británico (Harden, 1988, no 44). 

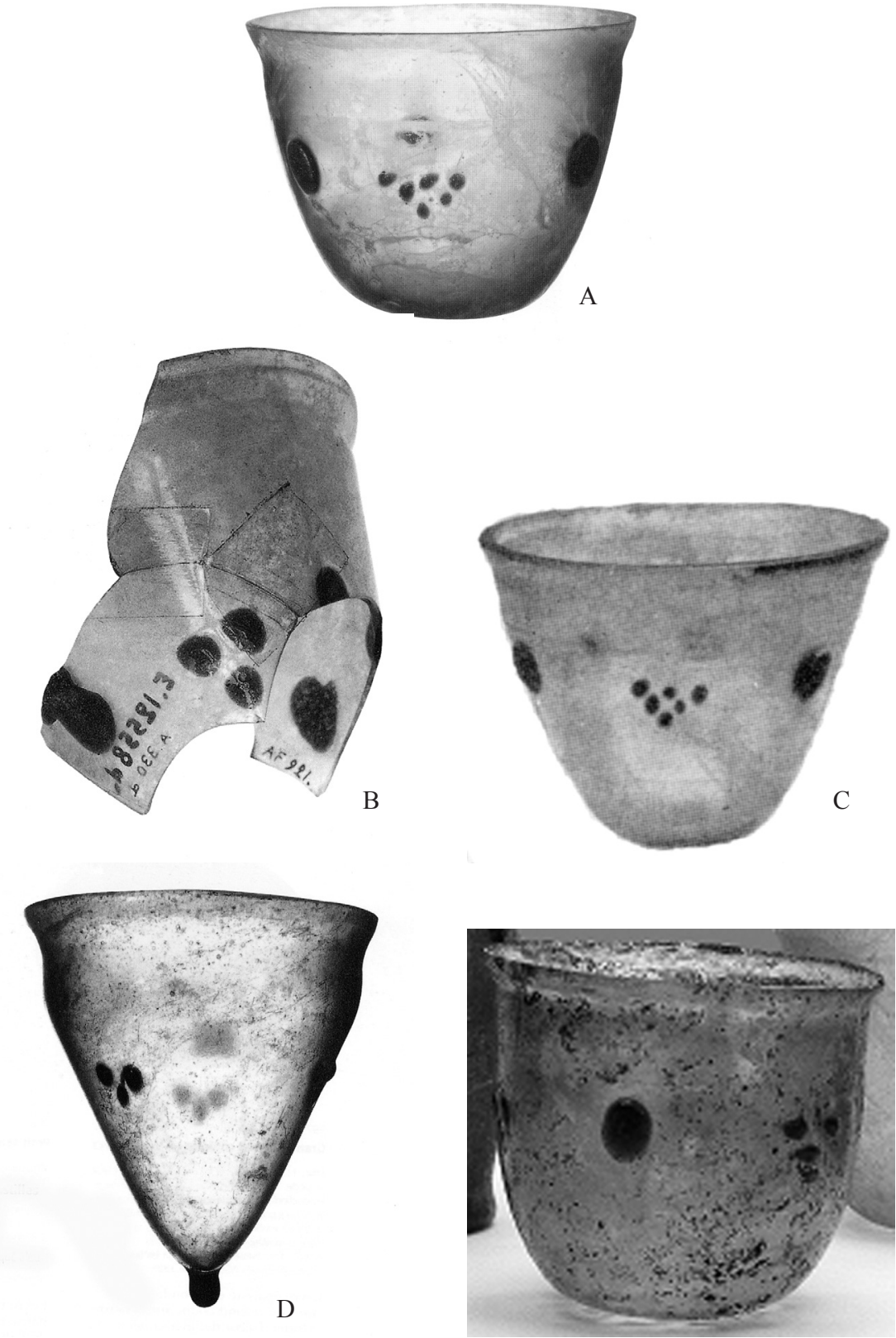

Figura 6: Cuencos con cabujones de procedencia oriental: a) Siria; b) Antinoe, Egipto; c) Saida, Fenicia; d) Siria; e) Kercht (según Arveiller-Dulong y Nenna).

resquebrajadura vertical en los cabujones grandes y restos de concreciones por varias zonas del depósito, especialmente alrededor de la decoración. La segunda pieza ofrece un depósito menos profundo, pero ambas han sido fabricadas con la misma técnica de vidrio soplado al aire, de grosor inferior a la aquí estudiada, incoloro y transparente pero con tonalidades ligeramente verdosas, como el cuenco de Madrid. Los depósitos de ambas piezas han sido ornamentados hacía su tercio medio por una ancha franja con varios cabujones siguiendo el tipo «a». Los grandes son de color azul más oscuro, y las pequeñas gotitas colocadas en racimo, en un tono azul algo más claro. Al igual que el ejemplar del Museo de Artes Decorativas, esta ancha franja decorativa aparece enmarcada arriba y abajo por varias líneas paralelas esmeriladas a torno y en frío sobre la pared del vaso, y una línea similar decora el borde de la embocadura.

El Metropolitan Museum de Nueva York posee otra pieza similar a las citadas del British Museum y a la del Museo de Artes Decorativas. El vidrio es igualmente incoloro, con algunas burbujas e irisaciones (Fig. 6,c). Su deposito, de forma cónica, es más alto y bastante profundo, con una embocadura algo más ancha que en el primer ejemplar del British Museum. Sus paredes están decoradas también con cabujones de tipo «a», con gruesos cabujones aplanados de color azul que alternan con racimos de seis gotitas de vidrio del mismo color. Este vaso procede de Saida, en Siria (Vigil, 1969, 196, Fig. 153). Otro fragmento 
de una pieza muy parecida conserva el Museo de Birmingham, de la misma cronología y procedencia oriental que los anteriores (Harden, 1988, 113).

Todos estos vasos son de segura procedencia oriental, fabricados con vidrios incoloros, decorados con los mismos tipos de los cabujones, grandes y pequeños, de color azul más o menos fuerte, dispuestos de la misma manera que en las piezas citadas halladas en Occidente y en la del Museo de Artes Decorativas de Madrid. Todos ellos han sido fechados en el siglo IV d.C., aunque ninguna de dichas piezas procede de un contexto arqueológico fechable.

El Museo del Louvre conserva también varios vasos de tipo «a», con las mismas características de vidrio incoloro, decoración de goterones en colores azul oscuro dispuestos de idéntica forma; al parecer, todos ellos también de procedencia oriental. Dos piezas, de origen fenicio y sirio (Fig. 6,a y d), han sido recogidas por Arveiller-Dulong y Nenna (2005, no 994 y 955), quienes las fechan en el siglo IV d.C. El fragmento ${ }^{\circ}$ 1211 (Fig. 6,b) corresponde a otra pieza de tipo «a», de vidrio igualmente incoloro con cabujones azules, que quizás fuera una lámpara, procedería de Antinoe, en Egipto, y se fecha algo más tarde, en el siglo IV-V d.C (ibidem). De Karanis, en Egipto, procede alguna pieza recogida por Harden (1936, $\mathrm{n}^{\circ} 331$ ), quien la fecha entre los siglos III-IV d.C., y el Museo del Louvre posee otra pieza similar a las anteriores por su decoración de cabujones del tipo «a», que procede de Kertch (Fig. 6,e), la antigua Panticapea, en el Mar Negro, fechada a fines del siglo IV o inicios del V d.C. (Arveiller-Dulong y Nenna, 2005: $\mathrm{n}^{\mathrm{o}}$ 1276).

También cabe citar varias piezas de colecciones españolas, aunque no halladas en la Península Ibérica, alguna de procedencia oriental. El Museo Arqueológico de Barcelona guarda un cuenco, más alto y profundo que el del Museo de Artes Decorativas, fabricado en vidrio de bastante buena calidad y color melado verdoso, que corresponde al tipo «b» por ofrecer una decoración más simple (Fig. 7), y que presenta en su tercio superior una única hilera de catorce goterones grandes de vidrio en forma de cabujones circulares irregulares de color azul violeta. Este ejemplar se fecha en el siglo IV d.C. (Carreras, 2004, $\mathrm{n}^{\mathrm{o}}$ 399) y, aunque carece de procedencia, se considera de origen oriental, pues su forma recuerda la de las piezas citadas de $\mathrm{Si}$ ria del Museo del Louvre y de Saida del Metropolitan Museum, aunque su decoración es del tipo «a» más variado. Otra pieza muy parecida a la del Museo de Artes Decorativas, asimismo sin procedencia segura, pertenece a la antigua Colección Ametller de Barcelona (Fig. 8). Es un cuenco ancho y profundo que podría considerarse una variante de la forma Isings 107. Presenta una única hilera de cabujones grandes del tipo «b», bastante irregulares y dispuestos alrededor del recipiente. La pieza fue adquirida en París y se supone que de fabricación occidental, tal vez de las Galias, $y$, como la anterior, se ha fechado en el siglo IV d.C. (Gudiol Cunill, 1925, n 27).

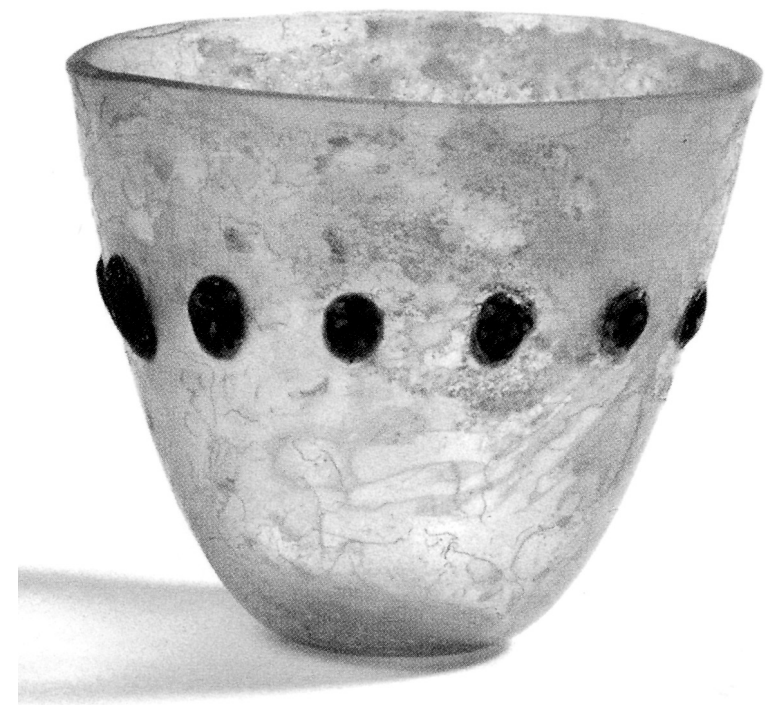

Figura 7: Cuenco del Museo Arqueológico de Barcelona (Carreras, 2004, n 399).

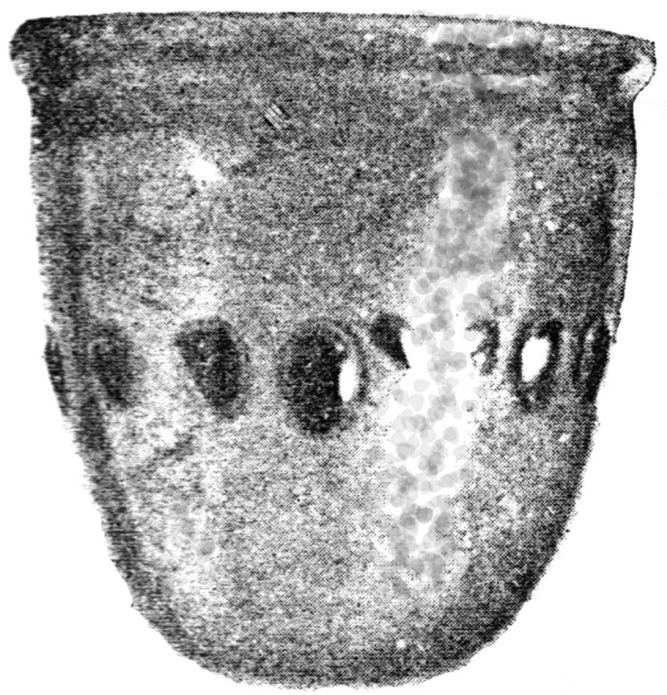

Figura 8: Cuenco de la Colección Ametller, Barcelona (según Gudiol, 1925, n²7).

Por otra parte, es interesante que vasos con este tipo de decoración están muy bien documentados en Europa Oriental, en Hungría y, sobre todo, en el Mar Negro, donde fueron bien estudiados por Sazanov (1995), quien les dedicó una monografía con una buena una tipología. Provienen principalmente de las regiones de Panticapea, Tiritaka, Charaks, Quersoneso, donde debieron producirse localmente, según tradiciones venidas de la zona siria-palestina, Panagoria, Hermonassa y Tanais, en las que aparecen en bastantes necrópolis bien datadas por sus ajuares, principalmente cerámicas romanas tardías y fíbulas. Por ejemplo, la tumba de Sovchov 10, cerca de Quersoneso, o la de Diurno, junto a Novorossijsk. Sazanov (ibidem) ha establecido tres tipos de formas esenciales y 18 tipos de decoración, que corresponden a cuatro etapas 


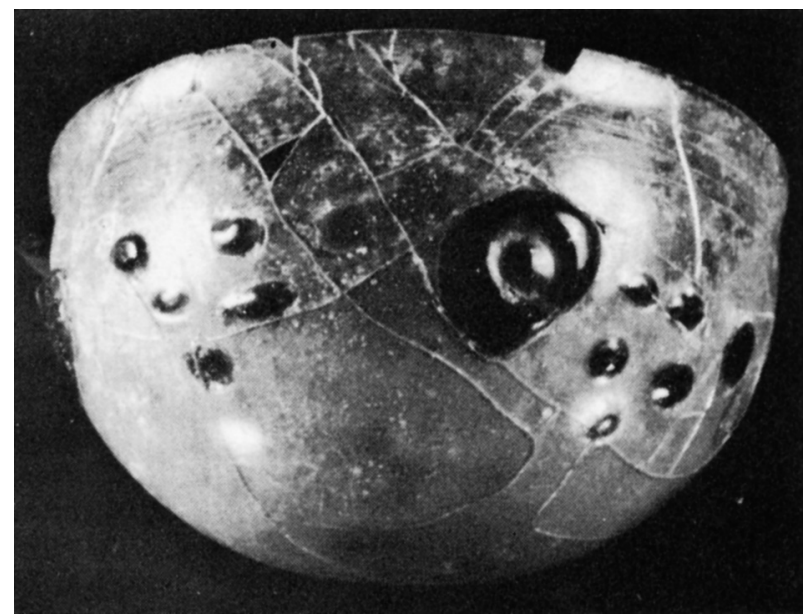

Figura 9: Cuenco del Museo de Estrasburgo (Arveiller-Dulong, 1985, 212).

cronológicas, desde el 350 d.C. al 550 d.C., y considera que existen dos lugares de origen para estas piezas. Una tradición oriental, de origen sirio, se fecha a partir de la segunda mitad del siglo IV d.C. y continúa en el siglo V d.C. Se caracterizaba por vidrio con composición de sodio-potasio-calcio-magnesio y sílice, realizada a partir de una mezcla de sodio-cal-arena, con importantes añadidos de óxido de potasio y magnesio con algo de plomo (Sazanov, 1995, 333-344, Fig. 1,b y 2), mientras que otra serie de piezas con cabujones las considera de fabricación y tradición occidental.

En Occidente, uno de los centros productores más reconocidos estaría en Colonia, donde se han hallado numerosos ejemplares, algunos muy originales y bellos, adornados todos con múltiples cabujones (Fremersdorf, 1962, 1967). Sin embargo, son también muy numerosos los ejemplares de este tipo hallados en Tréveris (Göethert-Polaschek, 1980, lám. 25, $\mathrm{n}^{\circ}$
5-7), Worms, Bonn, etc. (Vigil, 1969, Fig. 140, 157), y en múltiples lugares de toda Francia, sobre todo en la zona de Aisne, en las localidades de Sissi, Vermand y Sablonière (Fig. 3,c), donde apareció un cuenco de forma Isings 96 con decoración del tipo «a» similar al del Museo de Artes Decorativas (Morin-Jean, 1913, 221). También en Homblières (Somme) se halló otra pieza de vidrio con cabujones de este estilo, en una sepultura femenina, y existen ejemplares procedentes de múltiples localidades, como Reims (Fig. 3,d), Chalons, Bury, Boulogne-sur-Mer, etc. (Morin-Jean, 1913, 218-225). Recientemente, se han estudiado hallazgos de este tipo de cuencos decorados con cabujones de vidrio oliváceos de la Aquitania, pues se conservan varias piezas en el Museo de Burdeos, alguna procedente de la Villa de St. Sever, fechadas en los siglos IV-V d.C. (Foy, 1995, 156, 169, Fig. n 1-7). También aparecen en Martigny, en el Valais, con texturas del vidrio y cronologías similares a las anteriores (Martin, 1995, 93-107, Fig. 1). Igualmente, el Museo de Estrasburgo conserva cuatro piezas singulares, dos de ellas de tipo «a». La primera es un cuenco de forma Isings 96b (Fig. 9), que ofrece una franja de cuatro grupos de cabujones grandes en tonalidad azul violeta alternando con otra serie de seis pequeñas gotas de vidrio del mismo color formando triángulos, decoración casi igual a la pieza de Madrid, a varios ejemplares de Colonia recogidos por Fremersdorf $\left(1962\right.$, n $\left.^{\circ} 29,36,63\right)$ y también bastante parecida a otra del Museo de Segovia del tipo «b» (vid. infra), aunque, en el ejemplar de Estrasburgo y en alguno de Colonia (Fremersdorf, 1962, n 24, 27$28,56,60-62)$, los cabujones grandes son umbilicados. Otra pieza del Museo de Estrasburgo (Fig. 10,b) es de forma Isings 106, con decoración de tipo «a» repetida en dos franjas superpuestas arriba y abajo del vaso. Estos ejemplares de Estrasburgo se fechan en el siglo III-IV d.C., pues aparecieron en las excavaciones
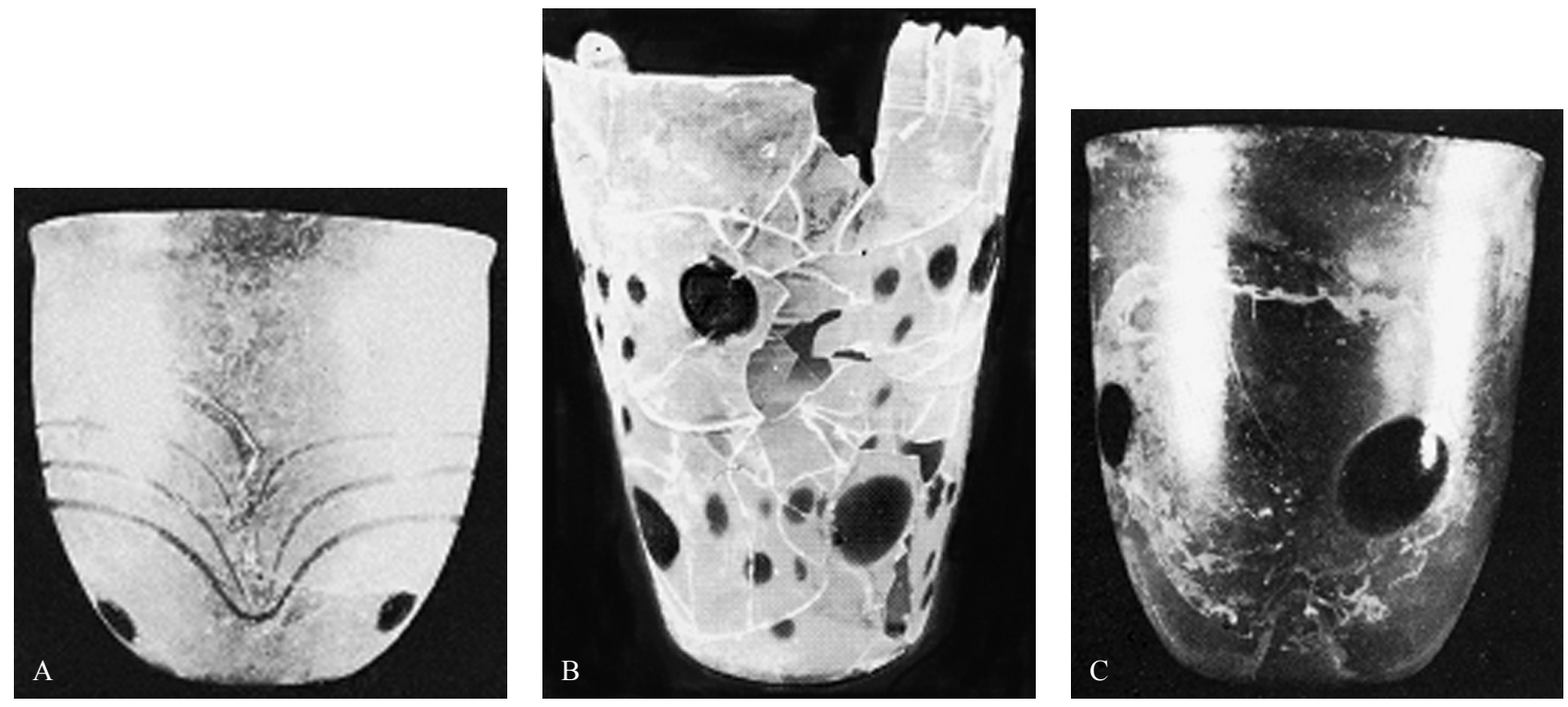

Figura 10: Cuencos con cabujones hallados en Estrasburgo (Arveiller-Dulong, 1985, 213). 

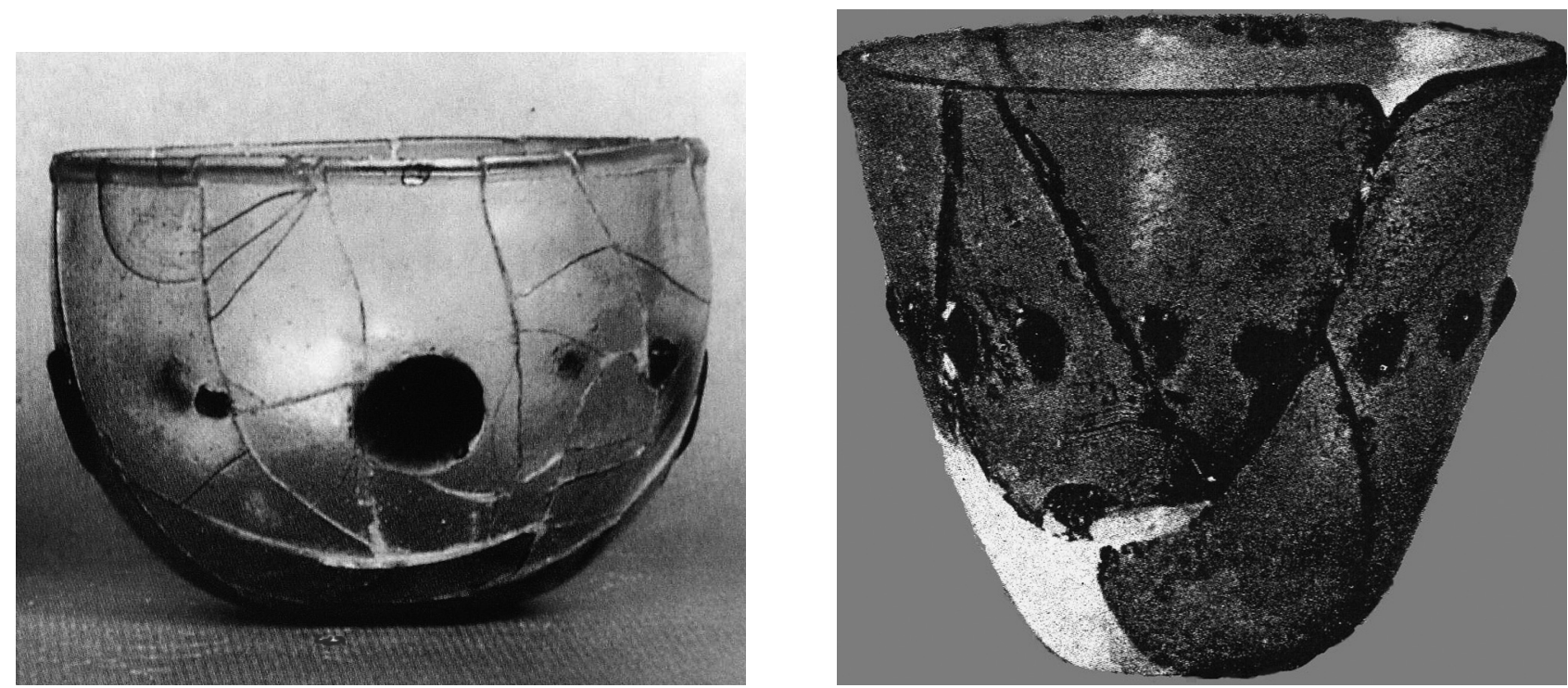

Figura 11: a) Cuencos de Roda de Eresma y de Hornillos del Camino (Molinero, 1971, lám. 107 y Mártinez Burgos, 1946, lám. 20,7).

del abate Straub en Strasbourg-Koenigshoffen, en el ajuar de sepulturas de inhumación del cementerio de la Porte Blanche, de época tardorromana (ArveillerDulong, 1985, 212-213), datos que coinciden con las fechas de Colonia, de Segovia y de otras parecidas en diferentes lugares de Hispania.

También se han encontrado bastantes piezas de vidrio decoradas con cabujones de tonalidades oliváceas en el Sur de Francia. En Marsella, en La Bourse y en La Lombarade, se fechan ya en la $2^{\mathrm{a}}$ mitad o fines del siglo IV y en el siglo V d.C., piezas consideradas en su mayoría de fabricación local (Foy, 1977, 277-86; 1984, 291-92, Fig. 1, no 2 y Foy, 1995, 187-242, Fig. 9). Igualmente, se han hallado en Porto Torres, Cerdeña (Villedieu, 1984) y, ya fuera de las Galias, se han documentado piezas de este tipo en Brigetio, Hungría (Barkóczi, 1968, 76-8, Fig 37), en Aquileia, (Calvi, 1968, nº 343) y en otros lugares de Italia (Sternini, 1995, Fig. 16; Curina, 1983,167), y también existen hallazgos de esta clase en Inglaterra (Cool, 1995, Fig. 3,3).

\section{LOS HALLAZGOS DE LA PENÍNSULA IBÉRICA}

La antigua Hispania también ha proporcionado hallazgos de este tipo de cuencos con cabujones, en su mayoría en excavaciones de estos últimos años bien documentadas, aunque todavía se discute si todas las piezas deben considerarse importaciones o si, como empieza a suponerse, muchas pudieron fabricarse en talleres locales hispanos, pues no debieron ser piezas excepcionales, sino bastante usuales, ya que, por lo general, los vidrios son de calidad mediocre, con numerosas burbujas (Xusto, 2001, 242, 253).

Estos vasos son relativamente frecuentes en $\mathrm{Co}$ nímbriga, donde se hallaron varios fragmentos de diferentes recipientes decorados con cabujones, algunos verdes de tipo «a» y otro con un cabujón azul, de tipo indeterminado (Alarção, 1976, n 260-61, 200 y 229), y también se puede citar algún ejemplar de Balsa, Tavira (Alarção, 1970, 237-262). Igualmente, han aparecido varias piezas en el Noroeste, en las provincias de Lugo (Carreño Gascón [dir.], 1995; Xusto, 2004, 242) y Orense (Xusto, 2004, 242).

El ejemplar de tipo «a» del Museo de Artes Decorativas de Madrid procede de Guarromán, Jaén (vid. supra), y ha sido considerada de origen bárbaro por Vigil (1969,157-8; Menéndez Pidal [dir.], 1940, 661). Otro cuenco completo se conserva en el Museo de Segovia (Fig. 11,a), bastante parecido al anterior por su forma, aunque no ofrece igual decoración, pues correspondería a un tipo «c», en el que alternan un cabujón grande con uno pequeño. Fue hallado en la sepultura de inhumación $\mathrm{n}^{\circ} 3$ de la necrópolis tardorromana de Roda de Eresma, Segovia, excavada oficialmente en 1950 por Antonio Molinero Pérez (1971, 22, lám. CVII), pieza conocida por haberse publicado varias veces (Fremersdorf, 1962, nº 62,b; Vidrio Romano en España, 2001). En dicha sepultura aparecieron, junto a este cuenco, un plato de vidrio de paredes altas, una jarra y una ollita de barro y diversas tachuelas y clavos de hierro, algunos del ataúd de madera del muerto. Todavía no se ha hecho un estudio actualizado de los materiales de la tumba ni del resto de las sepulturas de la necrópolis, por lo que se seguía manteniendo que este tipo de cuencos eran productos del periodo visigodo, dada su decoración con cabujones de ricos colores, imitando piedras duras al gusto del arte galo, pero también visigodo y bizantino, aunque en la actualidad se consideran de época tardorromana (Vidrio Romano en España, 2002, 168; Menéndez Pidal [dir.], 1940, 661).

Una tercera pieza decorada con cabujones de procedencia hispana, menos conocida que las citadas, procede igualmente de la provincia de Burgos, y se 

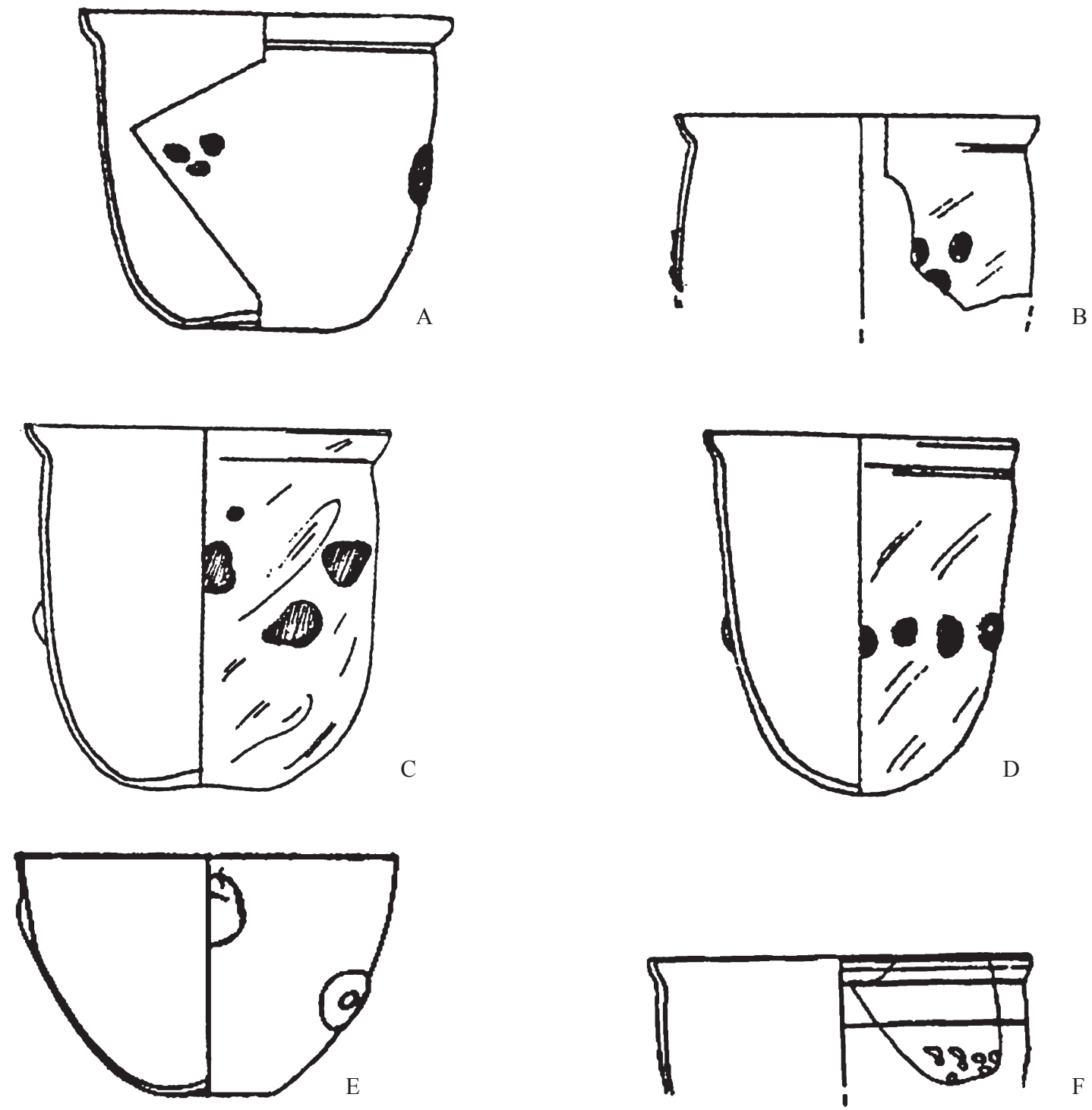

F
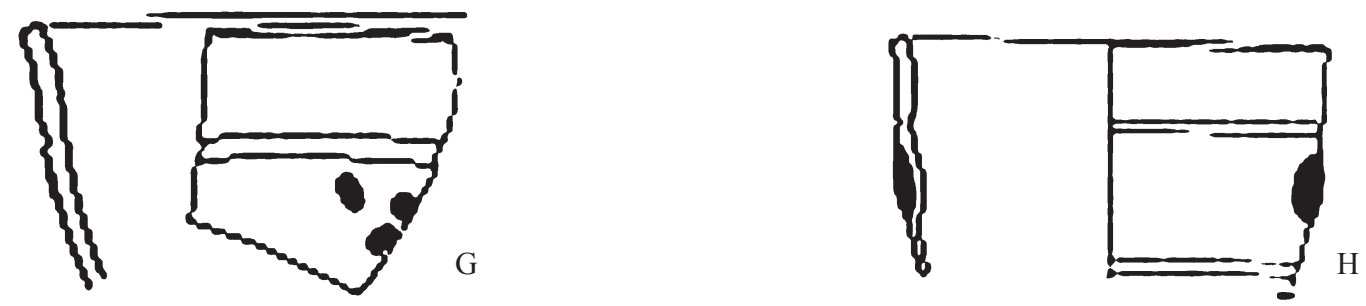

Figura 12: Cuencos con cabujones de tipo a y b de la Tarraconense litoral y el Valle del Ebro: a) El Albir; b) Baños de la Reina; c-d) Ilici, La Alcudia de Elche; e) Zaragoza; f) Castiliscar, Zaragoza; g-h) Baetulo (Sánchez de Prado, Ortiz Palomar y Flos).

encuentra en el Museo Arqueológico de esa ciudad (Fig. 11,b). Se trata de otro cuenco no muy grande, de sólo $8 \mathrm{~cm}$ de alto, fabricado en vidrio de grosor mediano y de calidad mediocre, ya que presenta bastantes burbujas e irisaciones. Es un cuenco o vaso de tonalidades incoloras variante de las formas Isings 106 o 107, aunque más próximo a la forma 106, que se caracteriza por una boca ancha y el depósito bastante profundo, tipo intermedio entre los cuencos cónicos y los elipsoidales. Presenta en el centro de sus paredes una decoración de tipo «b», compuesta por una hilera de dieciocho grandes y gruesos cabujones salientes, de forma circular ovalada, algo irregular, realizados en vidrio azul, adheridos en caliente a la pared externa del vaso y comparables a algunos ya citados (Figs. 2, 3,6 y 11,a). Su estado de conservación no es bueno, pues le falta gran parte del depósito y de la base, y sus paredes estaban resquebrajadas y rotas (Martínez 
Burgos, 1946, lám. XX, 7). Este vaso de vidrio fue entregado al Museo de Burgos el 23 de julio de 1945 por el P. Saturio González del monasterio de Silos (Martínez Burgos, 1946, 169), con otros noventa y seis objetos hallados en sus excavaciones en las necrópolis de Hornillos del Camino, Burgos. Entre estos objetos había cerámicas, varios ricos recipientes y adornos de bronce y otras piezas más de vidrio, todas ellas características de estas necrópolis tardorromanas. Entre éstas había otro cuenco de vidrio incoloro, de forma muy similar y de tamaño inferior a éste, pero sin decoración de cabujones, aunque sí con varias líneas paralelas esmeriladas a torno alrededor del borde y en el tercio superior del depósito, más un pequeño ungüentario o balsamario de forma Isings 68 y un par de cuencos de vidrio incoloro que pueden considerarse variantes de la forma Isings 42 (Martínez Burgos, 1946, lám. XX, $\mathrm{n}^{\mathrm{o}}$ 8-11). Matías Martínez Burgos (ibidem) consideró estos objetos de época visigoda, como ocurrió también con la anteriormente señalada de Roda de Eresma.

Otra pieza completa procede de la necrópolis de Cabriana, necrópolis tardorromana emparentada con las necrópolis del Duero y similares. Es un cuenco de vidrio incoloro decorado por toda su superficie con múltiples cabujones de vidrios de colores distintos. La tumba romana donde apareció, típica del Bajo Imperio, contenía unas tijeras y un cuchillo de hierro, una pequeña botella, un cuenco y una jarrita de barro, formas características de la baja época romana, que sitúan la tumba igualmente hacía la segunda mitad del siglo IV d.C. Por consiguiente, tal como documentan hallazgos más recientes en necrópolis tardías de este tipo de toda la Meseta, está fuera de toda duda que la mayoría de las citadas necrópolis y sus materiales deben situarse en el periodo tardorromano, no visigodo, aunque algunos materiales puedan llegar hasta fines del siglo IV o incluso el siglo V d.C. (Fuentes Domínguez, 1989, 1990; Caballero Zoreda, 1974, 145-153).

Algo similar cabe decir respecto a las múltiples piezas decoradas con cabujones aparecidas en yacimientos del Levante español, todas ellas del periodo tardorromano del Bajo Imperio. En efecto, existen piezas bien estudiadas con paredes decoradas con estos tipos de cabujones en yacimientos romanos de época tardía, en varios yacimientos de Alicante y de otros lugares, tanto en hábitats como en necrópolis, siempre fechados entre los siglos IV y V d.C. (Sánchez de Prado, 2004). Por ejemplo, dos ejemplares enteros de los tipos «a» y «b» proceden de Ilici, la Alcudia de Elche, (Fig. 12,c-d); fragmentos de tipo «a», de Baños de la Reina, Calpe (Fig. 12,b); una pieza casi completa de tipo «a», de El Albir (Fig. 12,a), en el ajuar de una tumba de la necrópolis I, y completan el panorama diversos fragmentos de El Monastil y El Alberri (Sánchez de Prado, 2004, 94). Igualmente, piezas de este tipo han aparecido en la antigua Tarraco, en un basurero de Vila Roma (Benet y Subiás, 1989, 331), y también hay varios fragmentos en Badalona, la antigua Baetulo (Fig. 12,g-h), aunque aparecidos sin contexto arqueológico (Flos, 1987, 85-86, 183, 199, Fig. 61, n 369-370 y Fig. 77, nº 466-467).

Recientemente se ha documentado un fragmento de cuenco de vidrio con un cabujón azul, al parecer de la forma Ising 96b2 (Fig. 12,e), aparecido en una estratigrafía de la calle Gabín de Zaragoza, en el nivel I.1.3 datado entre el 460-480 d.C. (Ortiz Palomar, 2001, 105-106, Fig. 56,2). Fragmentos de otros dos recipientes, uno de ellos un vaso del tipo Isings 106c, de cronología igualmente tardía, procede de la antigua Turiaso, actual Tarazona (Ortiz Palomar, 2001, 248, Fig. 3,e-f), y la otra pieza, seguramente de forma Isings 96b, con restos de cabujones deficientemente elaborados (Fig. 12,f), fue hallada en Castiliscar, Villa de San Román, al norte de la provincia de Zaragoza, en el nivel II,11, de una prospección que permite fecharlo en la segunda mitad del siglo IV d.C., entre el 350-400 d.C. (Ortiz Palomar, 2001, 307, 318, Fig. 78,2).

Por tanto, estas piezas ornamentadas con cabujones de vidrios de colores deben situarse también en Hispania en época tardía (Fig. 13), por lo general dentro del siglo IV a.C. y durante todo el siglo V. Según Sazanov (1990), en su estudio de estas piezas en Europa Oriental, los recipientes más antiguos serían los cuencos de forma troncocónica, datados entre el 380500 d.C., anteriores a los vasos elipsoidales, fechables entre el 380-600, más frecuentes en el siglo $\mathrm{V}$ y todavía utilizados durante todo el siglo VI, vasos que, en ocasiones, aunque no siempre, presentan en aquellas áreas decoraciones de goterones de vidrio distribuidos alrededor del recipiente de formas algo más variadas que los anteriores (Sazanov, 1995, 335).

Los orígenes de este tipo de vaso no están todavía muy claros. Tal vez se puede pensar en Oriente, en la zona de Siria-Palestina, de donde podrían haberse extendido posteriormente a Chipre, el Mar Negro, Italia, las Galias y las fábricas renanas de Colonia, en la que alcanzan su cenit, distribuyendo sus productos por todas las Galias y su entorno, como lo atestiguan hallazgos numerosos de Alemania, Francia, Países Bajos e Inglaterra. Desconocemos todavía cómo y cuándo exactamente este tipo de vidrio llegó también a Hispania, ya en época tardía, donde debió hacerse igualmente popular, pues son numerosos los ejemplares hasta ahora descubiertos en España y Portugal, hallazgos que se multiplican a medida que avanza el conocimiento del vidrio romano en Hispania. Parece lógico que algunos recipientes fueran primero de importación, pero después debieron fabricarse aquí, lo que explica los hallazgos documentados en diversas excavaciones arqueológicas.

El mapa de dispersión de los cuencos con cabujones en Hispania (Fig. 13) evidencia una relativa abundancia de estos productos tardíos encontrados en yacimientos de España y Portugal. En la zona oriental se extienden por las costas catalana y valenciana y, sobre todo, son abundantes en la provincia de Alicante, tal vez por haber sido allí bien estudiados y catalogados (Sánchez de Prado, 1984, 2001, 2004). Desde las 

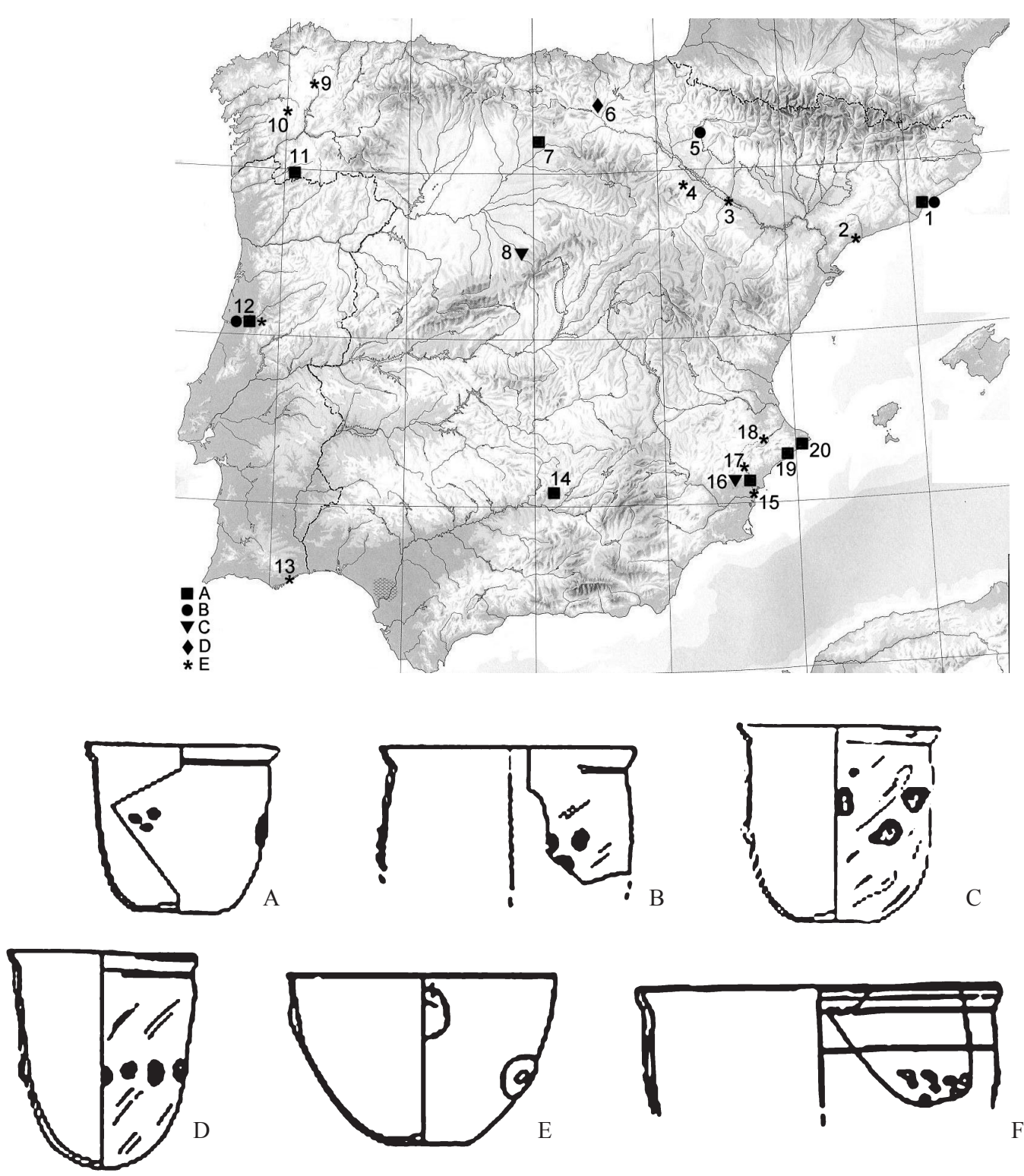

Figura 13: Hallazgos de cuencos y vasos con cabujones en la Península Ibérica (A, tipo «a»; B, tipo «b»; C, tipo «c»; D, ¿tipo renano?; E, incierto): 1, Baetulo, Badalona; 2, Vila-Roma, Tarraco; 3, Caesaragusta; 4, Turiaso, Tarazona; 5, Castiliscar; 6, Cabriana; 7, Hornillos de Camino, Burgos; 8, Roda de Eresma, Segovia; 9, Lucus Augusti, Lugo; 10, Santomé; 11, Riocaldo; 12, Conimbriga; 13, Balsa, Tavira; 14, Guarroman, Jaén; 15, Portus Ilicitanus; 16, Ilici, La Alcudia de Elche; 17, El Monastil, Elda; 18, El Alberri, Concentaina; 19, El Albir, Alfaz de Pi; 20, Baños de la Reina, Calpe.

costas del Levante se introducen por el cauce medio y alto del Ebro y sus afluentes, como indican los recientes hallazgos de la antigua Caesaraugusta y de otros lugares de la provincia, como Castiliscar y Tarazona, la antigua Turiaso, para pasar de la cuenca del Ebro al interior de la Meseta. En ésta se han documentado varios hallazgos de importancia en necrópolis tardías, en las provincias de Burgos y Segovia, bien fechados por sus ajuares a mediados y finales del siglo IV d.C., pues las sepulturas de Roda de Eresma, Hornillos del Camino y Cabriana ofrecen materiales emparentados de cronología muy similar, que entroncan con las necrópolis del Duero, de época tardorromana, bien estudiadas recientemente, lo que fecha con seguridad estos productos en Hispania hacia la segunda mitad del siglo IV d.C. o algo después (Fuentes Domínguez, 1989, 1990 y 2004). Es en este contexto en el que hay que valorar el interés del ejemplar del Museo Nacional de Artes Decorativas, hallado al parecer en Guarromán, en Jaén, hallazgo aislado hasta el presente, aunque seguramente enlazará en un futuro con los numerosos ejemplares documentados de Alicante.

A su vez, las piezas de vidrio decoradas con cabujones de la costa occidental de Hispania no son hallazgos aislados, pues cada día son más numerosos los hallazgos de estos tipos (Fig. 13), documentados en la Galaecia, en Santomé y Riocaldo, en Orense (Xusto, 2004, 242), pero también en Portugal, en Conímbriga 
y en Tavira, Balsa (vid. supra), y sabemos que existen vidrios tardorromanos decorados con estos tipos de cabujones gracias a los estudios realizados por J. Alarção $(1965,1970,1976)$, quien los ha dado a conocer ya hace tiempo en diversas publicaciones.

Los tipos de decoración de las piezas halladas en Hispania permiten observar que de Baetulo proceden diversos fragmentos con cabujones de color azul, alguno de ellos de una posible forma Isings 96, con decoraciones de tipo «a» $\mathrm{y}$ «b» encuadradas por líneas paralelas esmeriladas (Fig. 12,g-h). En Vila-Roma, en Tarraco, los tipos de los fragmentos encontrados no están muy bien definidos. En la provincia de Zaragoza se documentan varios tipos decorativos. En Caesaraugusta, los fragmentos encontrados corresponden a las forma Isings $96 \mathrm{~b}$ y 106 , pero son de tipo indeterminado, lo mismo que una pieza de Turiaso de la forma Isings 106c. Sin embargo, el fragmento de San Román, en Castiliscar, seguramente de forma Isings 96b, parece ser de tipo «a», pues conserva varias pequeñas gotitas azules dispuestas en racimo, aunque son de bastante mala ejecución. La pieza completa de Hornillos del Camino ofrece cabujones azules dispuestos con el esquema del tipo «b», y el cuenco Isings 96 de Roda de Eresma correspondería al tipo «c», más raro que los anteriores. Es también bastante excepcional la decoración de cabujones policromos que ofrece el pequeño cuenco hallado en Cabriana (Fuentes Domínguez, 2004, 306, Fig. 16), dispuestos alternativamente con diversos colores a lo largo del cuenco, sin seguir una estructura determinada, lo que recuerda algunas piezas de la Renania de los tipos f-g. Los ejemplares de la Galaecia son en su mayoría de tipo indeterminado, a excepción del ejemplar de Riocaldo, con decoración de tipo «a», que ofrece pequeñas gotitas de vidrio de tonalidad azul. En Portugal, en Conímbriga han aparecido fragmentos con cabujones tanto de tipo «a» como de tipo «b» e indeterminados, como indeterminados son también los fragmentos de Tavira. En la costa del Levante coexisten los dos tipos de decoración predominantes en estas piezas, pues en Ilici se han documentado fragmentos de cuencos con decoraciones tanto del tipo «a» como de un tipo que puede corresponder al «c», y, en El Albir y en Baños de la Reina en Calpe, han aparecido restos de cuencos con decoraciones claramente del tipo «a».

Los paralelos del Imperio romano analizados y los hallados en Hispania permiten comprender el interés de este cuenco de Guarromán de la Colección Sánchez Garrigós, que conserva el Museo Nacional de Artes Decorativas. Actualmente es la pieza de mejor calidad y la mejor conservada de todos los vasos de vidrio con decoración de cabujones hallados en Hispania. El vaso de la Colección Sánchez Garrigós corresponde al tipo «a», el más frecuente en el Imperio romano y también en Hispania, pero su interés radica en documentar cómo la tradición de esta vajilla de vidrio, que imitaba ricos vasos metálicos con cabujones, se mantuvo en Hispania hasta el final del Imperio romano, con calidades diversas, que indican diversidad de procedencias y una probable fabricación local de algunos productos, siempre asociados a niveles sociales elevados, tal como documentan los contextos arqueológicos en donde aparecen.

\author{
Dra. María José Almagro Gorbea \\ Museo Nacional de Artes Decorativas \\ c/ Montalbán, 12 \\ 28014 Madrid \\ josefa.almagro@mcu.es
}

\section{BIBLIOGRAFÍA}

ALARÇÃO, J. de, 1965: Vidrios romanos de Conimbriga, Conimbriga.

ALARÇÃO, J. de, 1970: «Vidrios romanos de Balsa», $O$ Arqueólogo Portugués, serie III, 4, 237-262.

ALARÇÃO, J. de, 1976: Les verres. Fouilles de Conimbriga VI. Céramiques et Verres, Paris.

ARVEILLER-DULONG, V. y ARVEILLER, J., 1985: Le verre de l'époque romaine au Musée Archéologique de Strasbourg, Paris.

ARVEILLER-DULONG, V. y NENNA, M.D., 2005: Les verres antiques du Musée du Louvre, II, Paris.

BENET, C. y SUBIÁS, E., 1989: «Els Vidres», en TED'A: Un abocador del segle V d.C. en el Forum Provincial de Tarraco, Tarragona, 329-377.

BARKÓCZI, L., 1968: «Die Datierten Glasfunde aus dem 3.4 Jahrhundert von Brigetio», Folia Archaeologica, 19, 59-86.

BARKÓCZI, L., 1972: «Spätrömische Glasbecher mit aufgelegten Nuppen aus Panonien», Folia Archaeologica, $23,78-87$.

BARKÓCZI, L., 1988: Pannonische Glasfunde in Ungarn. Studia Archeologica, 9, Budapest.

CABALLERO ZOREDA, L., 1974: La necrópolis tardorromana de Fuentespreadas (Zamora). Un asentamiento en el Valle del Duero, Excavaciones Arqueológicas en España 80, Madrid.

CALVI, M. C., 1968: I vetri romani del Museo d'Aquileia, Aquileia.

CARREÑO GASCÓN, C. (dir), 1995: Lucus Augusti, Urbs Romana. Los orígenes de la ciudad de Lugo (catálogo de exposición), Lugo.

CARRERAS ROSELL, T., 2004: Catàleg del Vidre antic del Museu d'Arqueologia de Catalunya, Monografies del Museu d'Arqueologia de Catalunya 5, Barcelona.

COOL, H. E. M., 1995: «Glass vessels of the forth and fifth century in Roman Britain», en D. FOY (ed.), Le verre de l'Antiquité tardive et du Moyen Age, Guiry-en-Vexin, 11-23.

CURINA, R., 1983: «Vetri», Ravenna e il Porto de Classe, Imola, 166-170.

FILARSKA, B., 1952: Szkla starozytne.I Katalog naczyn Muzeum Nadorowe w Warszawie, Varsovia.

FLOS TRAVIESO, N., 1987: Baetulo. Els Vidres, Badalona.

FOUET, G., 1969: La Ville gallo-romaine de Montmaurin (Haute Garone), XX Supplément à Gallia, Paris. 
FOY, D., 1976: «Verreries paléochrétiennes découvertes récemment à Marseille», Revue Archéologique de Narbonnaise, 10, 277-286.

FOY, D., 1995: «Le Verre de la fin du IV au VII siècle en France méditerranéenne», en D. FOY (ed.), Le Verre de l'Antiquité tardive et du Haut Moyen Age, Guiry-enVexin, 187-242.

FOY, D. ET ALII, 1998: Fouilles à Marseille. Le mobilier I-VII siècle a. JC, Études Massaliotes 5, 244.

FOY, D. y BONIFAY, M., 1980: «Eléments d'évolution des verreries de 1'Antiquité tardive à Marseille d'après les fouilles de la Bourse», Revue Archéologique de Narbonnaise, 17, 289-308.

FOY, D. y HOCHULI-GYSEL, A., 1995: «Le Verre en Aquitaine du IV au IX siècle, un état de la question», en D. FOY (ed.), Le verre de l'Antiquité tardive et du Haute Moyen Age, Guiry-en-Vexin, 151-176.

FREMERSDORF, F., 1928: Römischen Gläser aus Köln, Colonia.

FREMERSDORF, F., 1958: Römisches Buntglas in Köln. Die Denkmäler des römischen Köln III, Colonia.

FREMERSDORF, F., 1958b: Das Naturfarbene sogenante blaugrün Glas in Köln, Die Denkmale des römischen Köln IV, Colonia.

FREMERSDORF, F., 1962: Die römischen Gläser mit aufgelegten Nuppen, Die Denkmäler des römischen Köln VII, Colonia.

FREMERSDORF, F., 1966: «Die Anfänge der römischen Glashutten Kölns», Kölner Jahrbuch, 8, 24-43.

FREMERSDORF, F., 1967: Die Römischen Gläser mit Schliff, Bemalung und Goldauflagen aus Köln, Colonia.

FREMERSDORF, F., 1980: Römischen Glaser im Rheinischen Landesmuseum, Trier.

FUENTES DOMÍNGUEZ, A., 1989: La necrópolis tardorromana de Albalate de las Nogueras (Cuenca) y el problema de las denominadas «necrópolis del Duero», Cuenca.

FUENTES DOMÍNGUEZ, A., 1990: «Los vidrios de la Meseta. Ensayo preliminar de clasificación», Cuadernos de Prehistoria y Arqueología de la Universidad Autónoma de Madrid, 17, 169-201.

FUENTES DOMÍNGUEZ, A., 2004: «El Vidrio romano en la meseta», en Jornadas sobre el vidrio en la España romana, La Granja-2001, Cuenca.

GOETHERT-POLASCHEK,K., 1977:Katalogderrömischen Gläserdes RheinischenLandesmuseums Trier. Maguncia.

GOETHERT-POLASCHEK, K., 1980: Römischen Gläser im Rheinischen Landesmuseum, Trier.

GUDIOL Y CUNILL, J., 1925: Catàleg dels vidres de la Col·leció Amatller, Barcelona.

HARDEN, D. B. ET ALII, 1987: Glass of Caesars, Milan.

HARDEN, D. B. ET ALII, 1988: Vetri dei Cesari, Milano.

HARDEN, D. B., 1936: Roman Glass from Karanis, Ann Arbor, Michigan.

ISINGS, C., 1957: Roman Glass from dated finds, Groningen/Djakarta.

ISINGS, C., 1971: Roman Glass in Limburg, Groningen.

IVACHENCO, Y.: «Le Verre proto-byzantin. Recherches en Russie», en D. FOY (ed.), Le Verre de l'Antiquité tardive et du Haut Moyen Age, Guiry-en-Vexin, 319-330.
KISA, A., 1908: Das Glass in Altertume (Hirsemanns Handbucher 3), Leipzig.

MARTIN, Ch., 1995: «Le verre de l'Antiquité tardive en Valais», en D. FOY (ed.), Le Verre de l'Antiquité tardive et du Haut Moyen Age, Guiry-en-Vexin, 93-103.

MARTÍNEZ BURGOS, M. 1946: "Informe del Museo de Burgos», Memorias de los Museos Arqueológicos Provinciales 1946, 75, láms. 19-20.

MENÉNDEZ PIDAL, R. (dir), 1940: Historia de España, III. La España Visigoda, Madrid.

MOLINERO PÉREZ, A., 1971: Aportaciones de las Excavaciones y hallazgos casuales (1941-1959) al Museo Arqueológico de Segovia, Excavaciones Arqueológicas en España 72, Madrid.

MORIN-JEAN, 1913: La verrerie en Gaule sous l'Empire romain, Paris.

ORTIZ PALOMAR, E., 1997: «Estudio de colecciones de vidrio del Museo de Zaragoza I. Vajilla romana incolora», Arqueología Alavesa, 1993, 69-75.

ORTIZ PALOMAR, E., 1994: «Estudio de colecciones de vidrio del Museo de Zaragoza II. Vajilla romana», Arqueología Alavesa, 1997, 153-156.

ORTIZ PALOMAR, E., 2001: Vidrios procedentes de la provincia de Zaragoza. El Bajo Imperio romano. Catálogo de Fondos del Museo de Zaragoza, Zaragoza.

SÁNCHEZ DE PRADO, M. D., 1984: «El Vidre», Valentia Romana. Els Origens de la Ciutat, 39-40, Valencia.

SÁNCHEZ DE PRADO, M. D., 1984a: «El vidrio romano en la Provincia de Alicante», Lucentum, 3, 79-100.

SÁNCHEZ DE PRADO, M. D., 2001: «El Vidrio en Los Baños de la Reina, Calpe», I Jornades hispàniques d'història del Vidre, Monografies 1, 97-107, Barcelona.

SÁNCHEZ DE PRADO, M. D., 2004: «Vidrio romano en el Conventus Carthaginensis», Jornadas sobre el Vidrio en la España Romana, La Granja-2001, Cuenca.

SAZANOV, A., 1995: «Verres à décor de pastilles bleues provenant des fouilles de la Mer Noire. Typologie et chronologie», en D. FOY (ed.), Le verre de l'Antiquité Tardive et du Moyen Age, Guiry-en-Vexin, 333-334.

SOROKINA, N., 1967: «Das Antike Glas der Nordschwarzmeerküste«, Annales du 4e. Congrès International d'Études sur l'Histoire du Verre, Ravena-Venecia, 67-79.

STERNINI, M., 1989: Una manufatura vetraria di V secolo a Roma, Florencia.

VIDRIO ROMANO EN ESPAÑA, 2002: Vidrio romano en España. La Revolución del vidrio soplado, Real Fábrica de Cristales de La Granja.

VIGIL, C., 1969: El vidrio en el mundo antiguo, Madrid.

VILLEDIEU, F., 1984: Turris Libisonis. Fouilles d'un site romain tardif à Porto Torres, Sardaigne, BAR International Series, 224, Oxford.

XUSTO RODRÍGUEZ, M., 2001: «La Galicia romana y su "instrumentum domesticum"», en Jornades sobre el vidrio en España, Barcelona, 109-124.

XUSTO RODRÍGUEZ, M., 2004: «Vidrio de Gallaecia y del Norte Peninsular. Estado de la cuestión», en Jornadas sobre el Vidrio en la España romana, La Granja de San Ildefonso, 225-258. 